\title{
A PROBABILISTIC MODEL FOR THE DETERMINATION OF HYDRAULIC BOUNDARY CONDITIONS IN A DYNAMIC COASTAL SYSTEM
}

\author{
Jacco Groeneweg $^{1}$, Joost Beckers ${ }^{1}$ and Caroline Gautier ${ }^{1}$
}

\begin{abstract}
In 2011 new Hydraulic Boundary Conditions must be established for the statutory assessment of flood protection in the Wadden Sea area, which is a complex tidal system in the northern part of the Netherlands. The aim is to base these normative wave conditions on the wave simulation model SWAN and the probabilistic method Hydra-K, to be consistent with other systems as the Holland Coast and the Zeeland Delta. Assumptions made for the latter water systems, like steady state wind forcing, uniform water levels and neglect of currents, are not valid in the tidal basin of the Wadden Sea. A schematic temporal variation of both wind direction and wind speed is applied to define wind fields that drive the hydrodynamic computations. Both wind fields and resulting water level and current fields form the input of SWAN computations for a large number of combinations of basic wind speed and wind direction, offshore surge level and phase difference between tide and maximum wind speed. The result is a large database of SWAN results that is used as a lookup table in Hydra-K to transform the offshore statistics to the load on the primary sea defenses. In general the more advanced method leads to wave heights that are up to $10 \%$ lower and wave periods that are $10-20 \%$ smaller than those obtained with the method that is presently applied for the Holland Coast and the Zeeland Delta. These differences can be ascribed to the inclusion of currents and positive shoreward tilt in water level. The inclusion of relevant physics in the hydrodynamic computations increases the accuracy of the resulting HBC. Therefore, the more advanced method will be applied to determine the HBC for 2011.
\end{abstract}

Keywords: probabilistic method; wave modeling; tidal inlets; SWAN; Wadden Sea.

\section{INTRODUCTION}

A significant part of the Netherlands lies below sea level and is protected from flooding by dunes and dikes. In compliance with the Flood Defenses Act ("Waterwet, 2009"), the safety of the Dutch primary sea defenses must be assessed every five years for the required level of protection. This assessment is based on the Hydraulic Boundary Conditions (HBC) and the Safety Assessment Regulation. The HBC represent the hydraulic load (water level and wave conditions) that a flood defense must be able to withstand.

Following these regulations, the HBC for the Holland Coast and the Zeeland Delta (see Fig. 1) have been recalculated in 2006, using a probabilistic method, based on observed characteristics of storm events and empirical probability functions of wind speed, wind direction and water level. An important part of the HBC calculation is the transformation of offshore conditions to nearshore locations. For this purpose, the wave simulation model SWAN is used, or more precisely, a database with pre-calculated SWAN results.

In contrast to the Holland Coast and the Zeeland Delta no recalculation was done in 2006 for the Wadden Sea, because of lack of data for calibration and validation of SWAN in the Wadden Sea. The Wadden Sea is a complex area of tidal channels and flats. It is sheltered by barrier islands, especially in the western part. The eastern part is more open to the North Sea. In between Germany and The Netherlands the Eems-Dollard estuary is located (see Fig. 1).

In the so-called SBW ("Strength and Loading of Sea Defenses") project the performance of SWAN has been investigated in detail, leading to subsequent model improvements (Van Dongeren et al., 2010). The general opinion is that there is now sufficient confidence to apply the improved SWAN model in the 2011 edition of the HBC for the Wadden Sea.

\section{DRAWBACKS OF ORIGINAL MODEL FOR APPLICATION IN THE WADDEN SEA}

\section{Original model for determining HBC for Dutch coast}

The HBC represent the hydraulic load (water level and wave conditions) that is expected to be exceeded in a statutory return period. For the coast of Holland this return period is 10,000 years. For the Frisian and Groningen Wadden Sea coast it is 4,000 years for the mainland and 2,000 years for the barrier islands. The HBC for locations along the Dutch coast have been computed using the computer program Hydra-K. Hydra-K uses a probabilistic method, based on observed characteristics

\footnotetext{
${ }^{1}$ Deltares, P.O. Box 177, 2629 MH, Delft, The Netherlands (E-mail: Jacco.Groeneweg@deltares.nl)
} 
of storm events and empirical probability distribution functions of wind speed, wind direction and water level. This method generates combinations of extreme water level and wind occurrences, using the assumption of asymptotic dependency, i.e. that the observed correlations between these variables also hold for extreme conditions (De Haan and Resnick, 1977).

An important part of the HBC calculation is the calculation of nearshore wave conditions for a given combination of wind and water level at the location of interest. For several combinations of local water level, wind speed and wind direction, the nearshore wave conditions are pre-calculated using SWAN. The SWAN results are stored in a database, which forms a transformation matrix. This matrix is used as a look-up table in Hydra-K for transformation of a water level at a location of interest, wind speed and wind direction to the nearshore wave conditions.

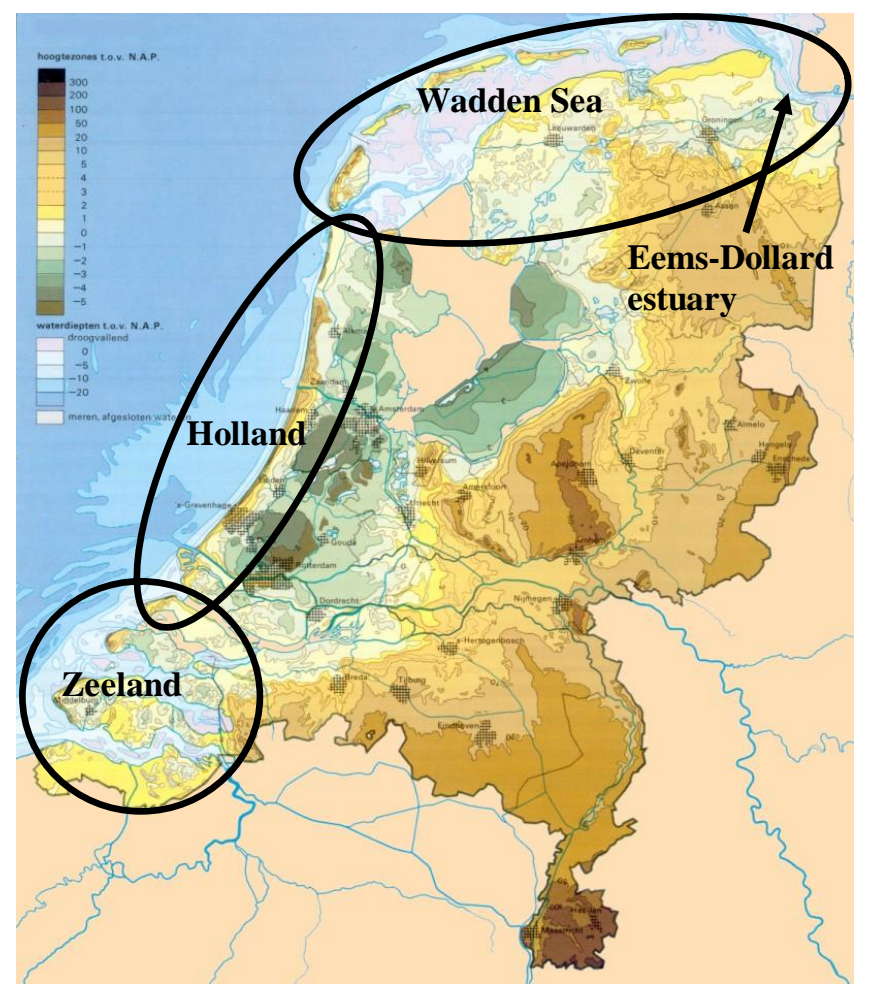

Figure 1. Map of the Netherlands, indicating the coastal area, including the Eems-Dollard estuary.

For the Holland coast the HBC have been derived by applying Hydra-K and SWAN (Groeneweg et al., 2006). Wind speed statistics have been based on Wieringa and Rijkoort (1983), who derived spatial patterns of extreme wind speeds based on the extreme value statistics of mostly land-based measurements. Water level statistics have been determined from long-term measurements at coastal stations spread along the Dutch coasts. Within Hydra-K the statistics at these reference locations are applied. The water levels at nearshore locations are obtained by interpolation between reference locations.

In the SWAN computations offshore wave conditions were deterministically derived from wind speed and direction. A wind field was imposed that varies only in North-South direction, based on the statistics in the most northern (Texelhors) and southern (Hoek van Holland) reference location. Furthermore, the water level was assumed to be uniform and currents were neglected.

A look-up table of SWAN results was created by considering the computed wave conditions at nearshore locations for a finite number of combinations of the Hydra-K random variables wind speed, wind direction and water level (see Groeneweg et al., 2006). The SWAN computations were carried out in stationary mode.

An obvious approach would be to apply a similar approach for the Wadden Sea area. Then, the wind and water level statistics that was derived for the HBC in 2006 is to be applied and wind fields 
(speed and direction) and water level fields are assumed to be uniform. Furthermore, currents are neglected. By performing stationary SWAN computations for the following combinations of random variables a look-up table is defined for what is referred to as method 1 :

- 5 wind speeds: $20,25, \ldots, 40 \mathrm{~m} / \mathrm{s}$

- 12 wind directions : full circle with $30^{\circ}$ interval

- 7 water levels: $1,2, \ldots, 7 \mathrm{~m}+\mathrm{NAP}$

where NAP denotes the Dutch reference datum.

\section{Relevance of storm dynamics in Wadden Sea}

The assumptions of a steady-state wind forcing, uniform water levels and absence of currents are invalid in the tidal basin of the Wadden Sea. Depressions pass over the North Sea causing a change in wind direction, typically from south-south-west to north-north-west. The changes in wind speed and wind direction have a significant effect on the hydrodynamics in the Wadden Sea. A detailed analysis of the characteristics of historical storms generating severe surges in the Wadden Sea (Alkyon, 2008) shows that high water levels were generated by rising wind speeds with directions approximately shifting from near-south to near-north. This is illustrated for the storm of November 1, 2006 in Fig. 2. During this storm the water level reached the crest of the dike at some locations in the Wadden Sea.

The historical time- and space-varying wind fields were tentatively schematized by synthetic steady-state values to carry out numerical experiments. Simulations with the hydrodynamic WAQUA model applied to the CSM-ZUNO-Kuststrook nested domains showed that the wind field cannot be simplified as a stationary wind field with constant speed and/or direction, if physicallybased speeds have to be maintained. The water level at a typical location in the eastern part of the Wadden Sea, computed from forcing with a spatially and temporarily varying wind field, cannot be reproduced if simplified wind fields are imposed (see Fig. 3). The peak tide free-water level is significantly underpredicted if the wind speed and direction are spatially uniform, although still varying in time. If the temporal variation is removed from the wind speed and/or wind direction even an increase of the surge cannot be obtained.

The highest water levels are typically observed if a western storm drives the water into the Wadden Sea and then turns northwest to north, forcing the water towards the mainland and into the Eems-Dollard estuary in the eastern part of the Wadden Sea. As illustrated in Fig. 3 a steady-state wind forcing is not considered a realistic approximation. The neglect of the temporal change in wind direction prevents the surge from increasing to the level that is obtained in case of unsteady wind forcing.

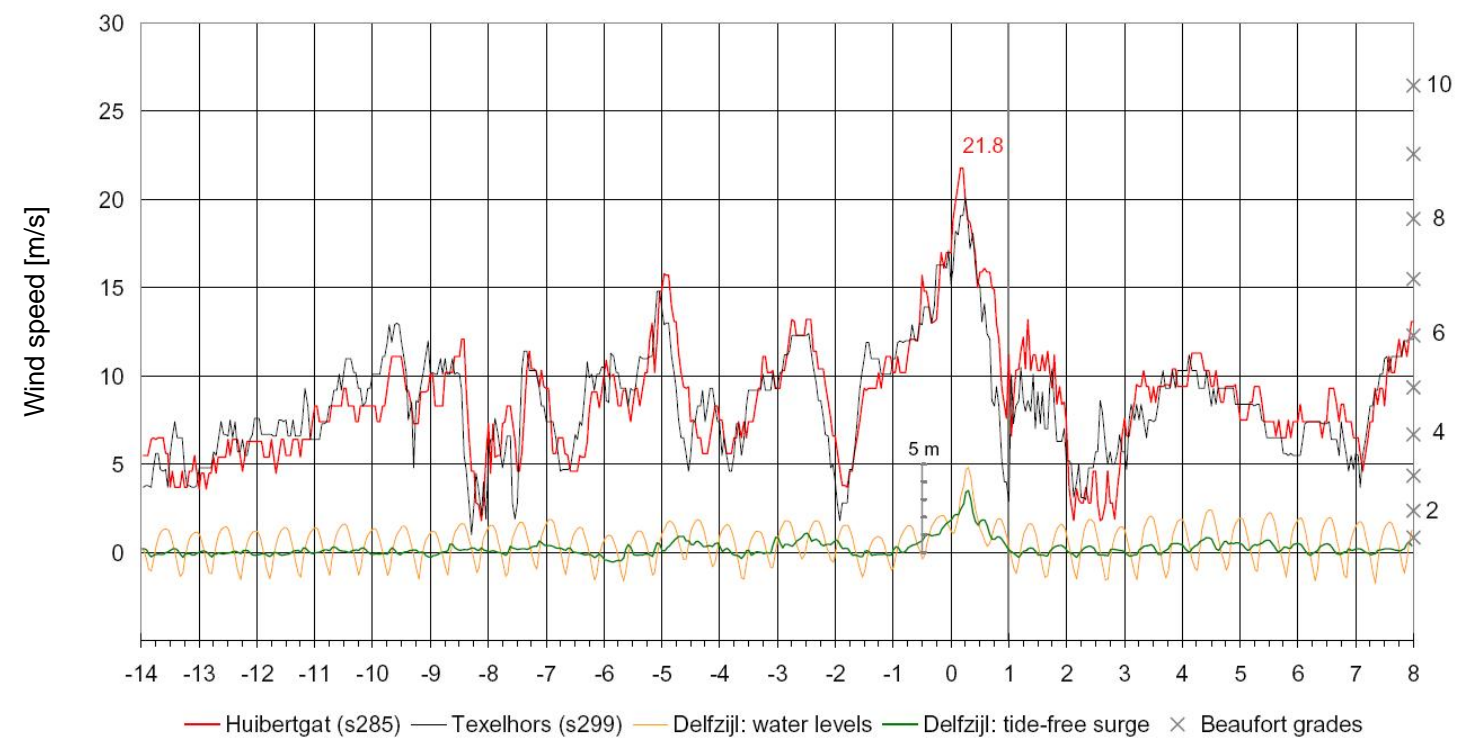




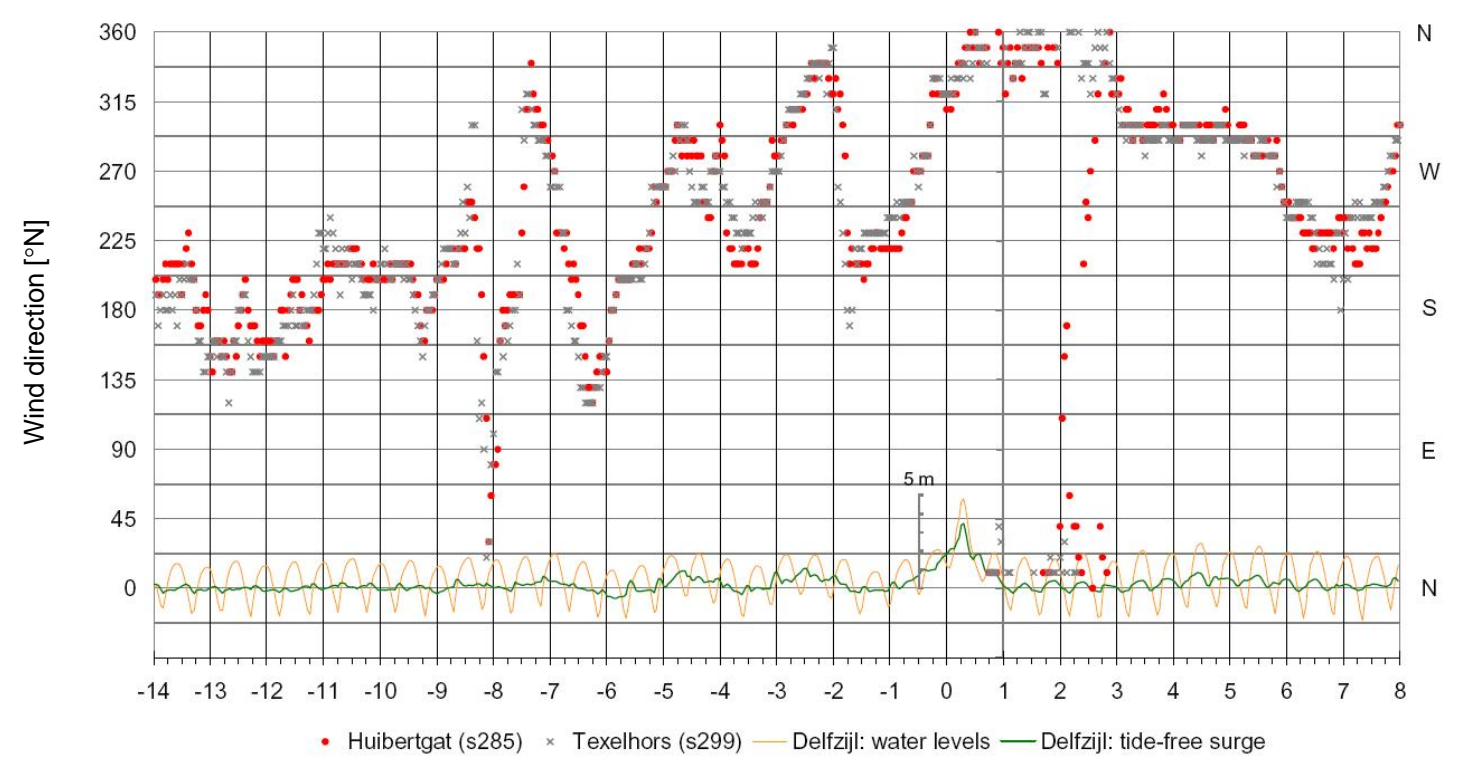

Figure 2. Histories of wind speed (upper panel) and direction (lower panel) from the measurement locations Huibertgat and Texelhors, against time in a three-week time interval around November 1, 2006. Total and tidefree water levels (in $\mathrm{m}+\mathrm{NAP}$ ) at tide gauge Delfzijl are given in the lower bands.

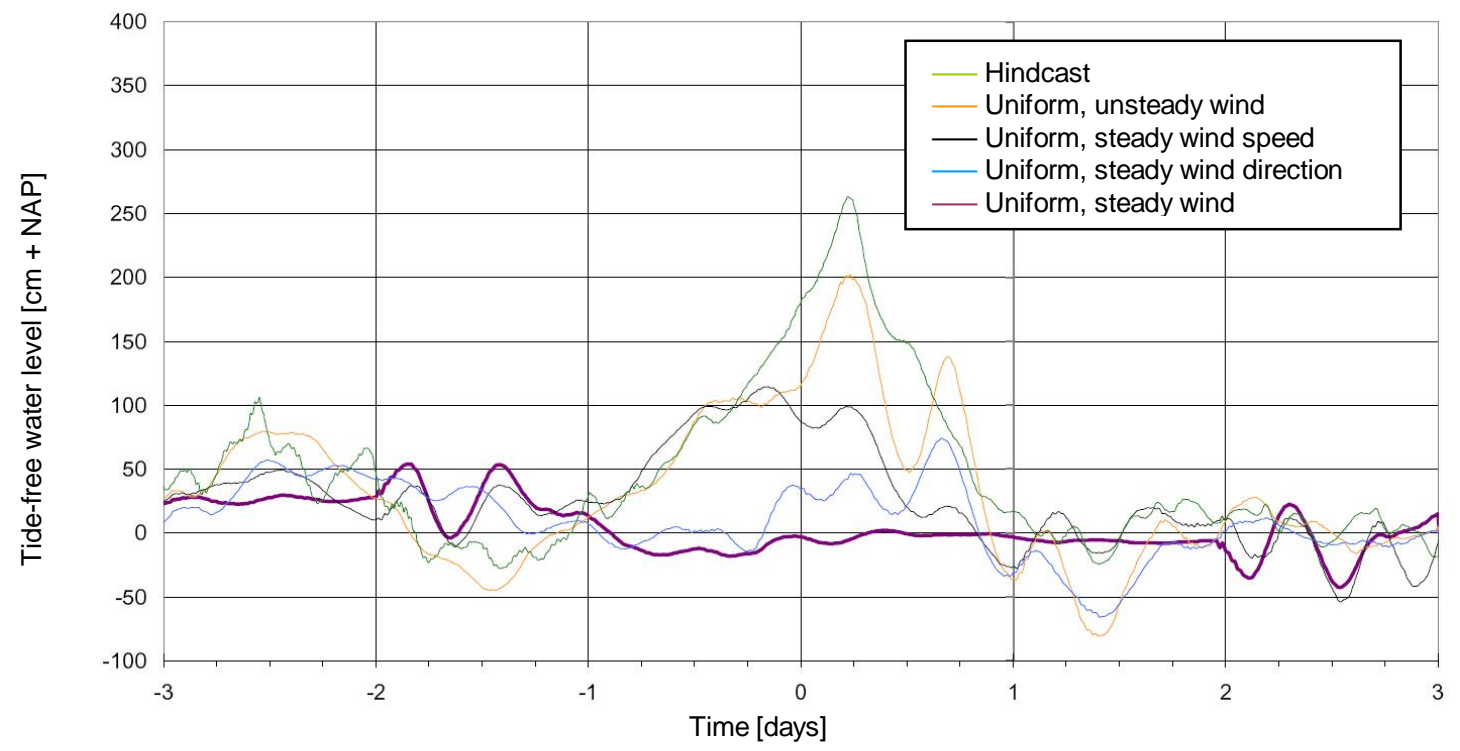

Figure 3. Computed tide-free water levels at a representative location in the eastern part of the Wadden Sea. Green line: unsteady forcing (based on measurements); Purple line: Uniform wind field; Other lines: variants with fixing either wind speed or wind direction.

\section{Currents in the Wadden Sea}

Van Dongeren et al. (2010) show that inclusion of currents improve the results of storm hindcasts in the Wadden Sea significantly. When waves experience a following current their effective wave age increases and thus the growth in the wave height and mean wave period decreases. In the case of opposing currents wave height and wave period will increase compared to the situation without current.

In the more extreme situations the wind-induced current component will dominate the tidal component and the waves and currents will be more or less aligned. Fig. 4 shows a snapshot of the current field during flood in the November 1, 2006 storm. The wind speed is over $20 \mathrm{~m} / \mathrm{s}$ from the North. The differences in computed significant wave height and mean wave period without and with current are shown in the lower panel of Fig. 4. The areas near the mainland are depth-dominated 
and the waves are fully saturated. The effect of currents on the wave height is therefore limited. The mean wave period however decreases significantly when current is included, in the Eems-Dollard estuary even more than 20\%. This stresses the importance of inclusion of currents in the computations that provide the look-up table for Hydra-K.
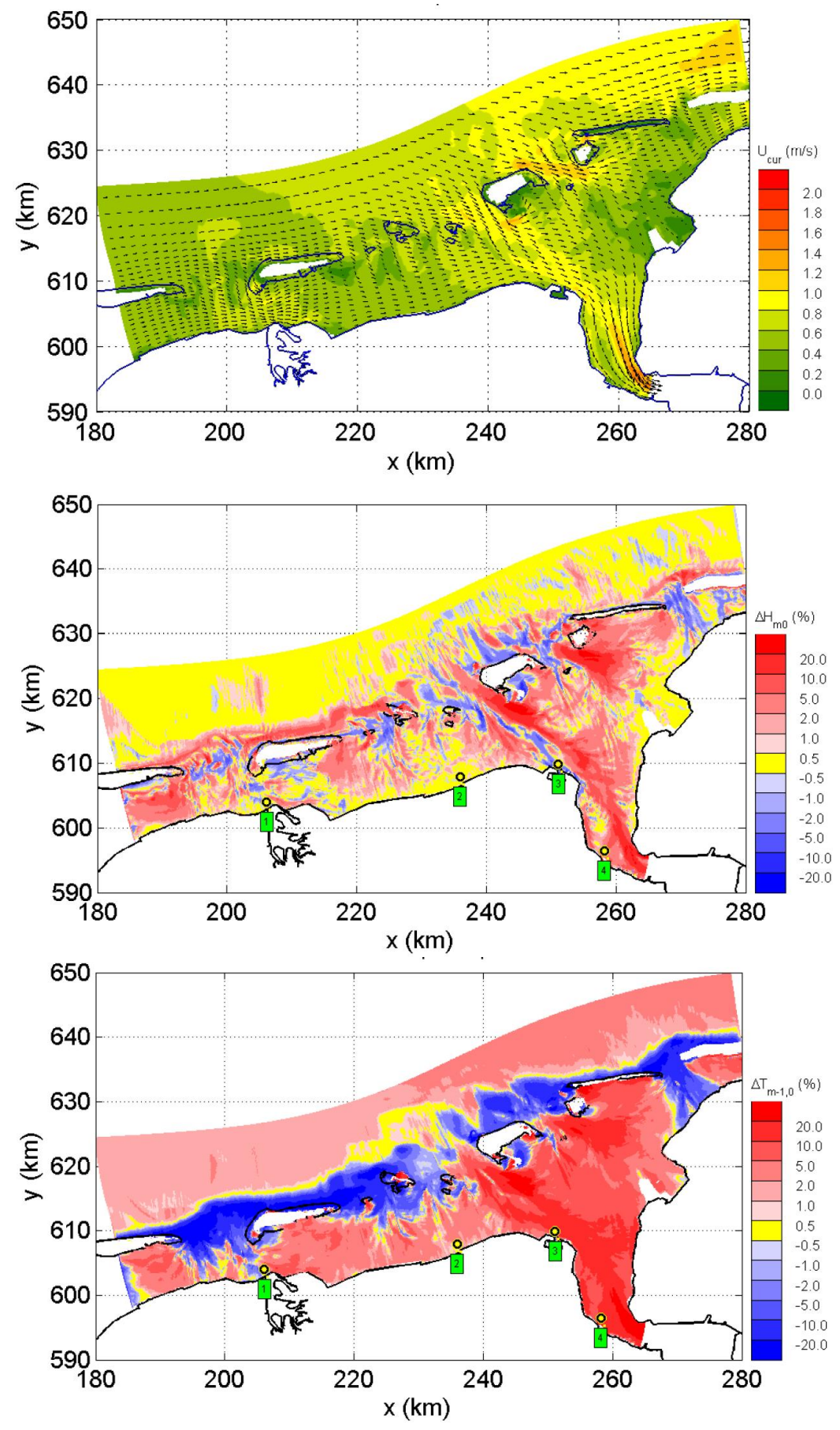

Figure 4. Upper panel: Computed current field for the storm of November 1, 2006 (4:00PM CET). Middle panel: Difference in significant wave height $H_{m 0}$ for situation without and with current $\left(\Delta H_{m 0}=H_{m 0}\right.$, no current $-H_{m 0}$, with current). Lower panel: same for mean wave period $T_{m-1,0}$.

\section{ADJUSTMENT OF ORIGINAL PROBABILISTIC MODEL}

By allowing the wind and water level to vary in time, the number of possible combinations increases dramatically. The standard approach for this would be to define a set of determining 
stochastic variables that describe the temporal variation of wind and water level, determine their (correlated) probability distributions and make a probabilistic calculation. However, this approach would require an accurate description of the multivariate probability distribution, and a redesign of the probabilistic model Hydra-K, which is considered not to be feasible before 2011.

An alternative method is proposed here that is based on the current Hydra-K model. A time dependency has been introduced in the wind (speed and direction), based on 75 historical storms. Each temporarily varying wind field is input for the hydrodynamic model WAQUA and the wave model SWAN, leading to time series of currents, water levels and wave conditions. A selection of time instants around the peak of the storm has been considered. The obtained wave conditions, which are still a function of wind and water level are interpolated to a regular matrix of these variables. The result is a look-up table in a format that can still be used by Hydra-K, but does include the effect of currents and temporal variations in the wind field. This advanced method is referred to as method 2 .

\section{Temporal evolution of wind speed and direction}

The rate of changing wind speed and wind direction of the model storms was taken from an observed set of real storms (Deltares, 2009). Storms were selected using a threshold of $20 \mathrm{~m} / \mathrm{s}$ (western storms) or $15 \mathrm{~m} / \mathrm{s}$ (eastern wind). All selected storms were re-scaled by dividing the wind speeds by the storm peak value. A symmetric trapezium with a top plateau of 1 hour was used to describe the temporal evolution of the wind speed. The temporal evolution of the wind direction was derived using the change in direction relative to the direction of the peak wind speed. This change in wind direction was averaged over all western storms and an error function was fitted to the result (see lower panel of Fig. 5). The schematized temporal evolutions of wind speed and direction were used as input for the WAQUA simulations. For eastern storms no typical pattern in wind direction could be derived from the observed storms, so a constant wind direction was assumed.

\section{WAQUA and SWAN simulations}

For several basic combinations of wind speed and wind direction temporarily varying, but spatially uniform wind fields are defined with the standard storm profile, see above. The WAQUA and SWAN simulations were set up such that they efficiently sample from a wide range of water levels under different conditions. This was done by applying a fixed offshore surge of 0,2 or $4 \mathrm{~m}+$ NAP at the offshore boundaries, an average tide and three different tide phase shifts of 0,4 and 8 hours with respect to the peak of the storm (wind speed maximum). These phase shifts will produce different results at nearshore locations, because tide interacts with the changing wind. Especially for the less extreme wind speeds the relative importance of the tide becomes larger.

The following values for the different variables were used:

- 8 peak wind directions: $0,90,180,210,240,270,300$ and $330^{\circ} \mathrm{N}$

- 5 peak wind speeds: $20,25,30,35$ and $40 \mathrm{~m} / \mathrm{s}$

- 3 tidal phases: 0, 4, 8 hours between peak wind and max. water level

- 3 offshore surge levels: $0,2,4 \mathrm{~m}+\mathrm{NAP}$

Note that eastern wind directions are sparse, while western wind directions are sampled more intensely, for obvious reasons. For 360 combinations of wind speed, wind direction, tidal phases and offshore surge level the WAQUA model provides time series of water level and current during the schematized storm.

Five time instants were selected from each WAQUA time series to provide input for a SWAN simulation. Each time instant represents a possible realization of a water level, wind and wave condition. The five time instants are chosen at 1 hour intervals (in order to reduce the number of data points) starting 2 hours before the peak of the storm up to 2 hours after the peak.

The current and water level fields from WAQUA were used as input to a stationary SWAN simulation. The wind fields in the SWAN simulations were taken spatially uniform, as in the WAQUA simulations. The WAQUA and SWAN simulations thus produce samples of wind and local water levels with corresponding nearshore wave conditions at each location. These are stored in a temporary database: a list of samples of nearshore wave conditions for various values of local water level, wind speed and wind direction. 

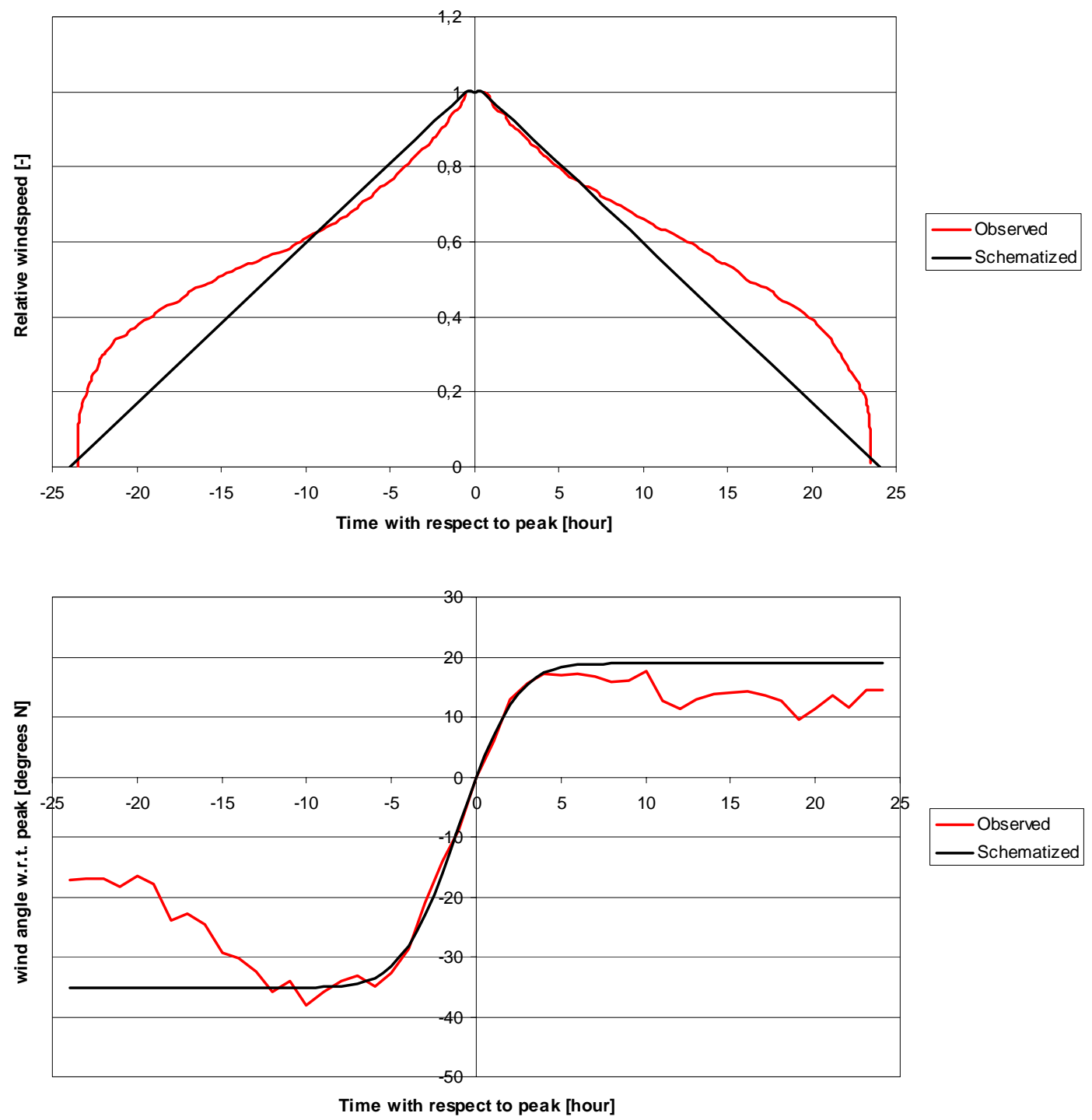

Figure 5. Standard temporal evolution of the wind speed (upper panel) and wind direction, relative to the direction of the peak wind speed, schematized by an error function (lower panel).

\section{Interpolation to a regular grid}

The water levels and wind speeds in the temporary database differ from the regularly spaced values that Hydra-K needs as input. In method 1 , the required water levels for Hydra-K are $1,2, \ldots$, $7 \mathrm{~m}+\mathrm{NAP}$ and the wind speeds are 20, 25, 30, 35 and $40 \mathrm{~m} / \mathrm{s}$. Method 2 produces a temporary database of SWAN results for deviant values of water level and wind (e.g. 1.5 or $1.6 \mathrm{~m}+\mathrm{NAP}$ and 21 or $23 \mathrm{~m} / \mathrm{s}$ ). The nearshore wave conditions at the regular values required by Hydra-K are determined by interpolation between the values in the temporary database. From several available techniques, the best results have been obtained by fitting a higher order polynomial to the data in the temporary database and calculating the values at the regular grid points for the Hydra-K database. This is done for each location separately. The procedure is visualized for 1D in Fig. 6.

Using the polynomials, we can also recalculate the $\mathrm{H}_{\mathrm{m} 0}$ and $\mathrm{T}_{\mathrm{m}-1,0}$ at the original values of the water level, wind speed and wind direction in the temporary database. The difference between the reconstructed values from polynomial and the original values in the temporary database gives an impression of the goodness of fit, or the scatter of the data around the 3D hypersurface. It was found that the RMSE of this difference is usually less than $10 \%$ for a particular location in the Wadden Sea and the largest deviation is less than $30 \%$. Small deviations are found for shallow water locations, because depth-induced wave breaking dominates all other processes. The largest deviations occur for 
locations where currents play an important role. Varying conditions (incoming or outgoing tide) can have a significant effect on the wave height and period. In most cases, a fourth order polynomial was found to give the best results. If this resulted in wave heights that are more than $20 \%$ larger than the highest wave height in the temporary database, then the polynomial was reduced to $3^{\text {rd }}$ order and if necessary to $2^{\text {nd }}$ order. The same procedure was applied to other wave parameters.

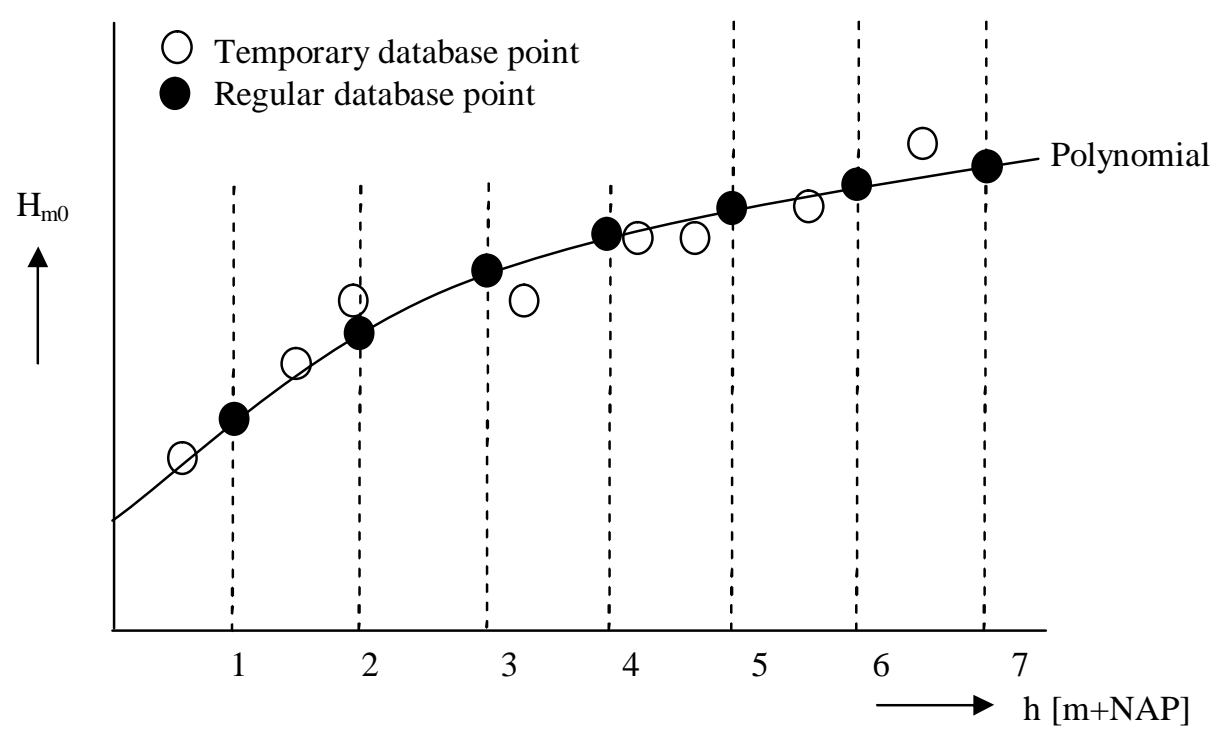

Figure 6. Schematic 1D representation of the translation of the temporary database SWAN data to the regular Hydra-K database values. In reality the translation is 3D, with wind speed and wind direction being the additional dimensions.

\section{RESULTS}

In this section the resulting normative wave conditions are presented, which are obtained from Hydra-K for the two methods described in the previous sections. The original SWAN grid of the Wadden model contains in the order of 2.5 million active grid points. This number is to large to perform thousands of SWAN simulations just to compare the results of methods 1 and 2 . Therefore all computations have been performed on the coarser Kuststrook-Fijn grid (see Fig. 7). The grid resolution near the coast is relatively coarse: approximately $100 \mathrm{~m}$ in cross-shore direction. This will affect the nearshore wave conditions. Nevertheless, the indicative SWAN results are considered sufficiently accurate to make a qualitative comparison between method 1 and 2 .

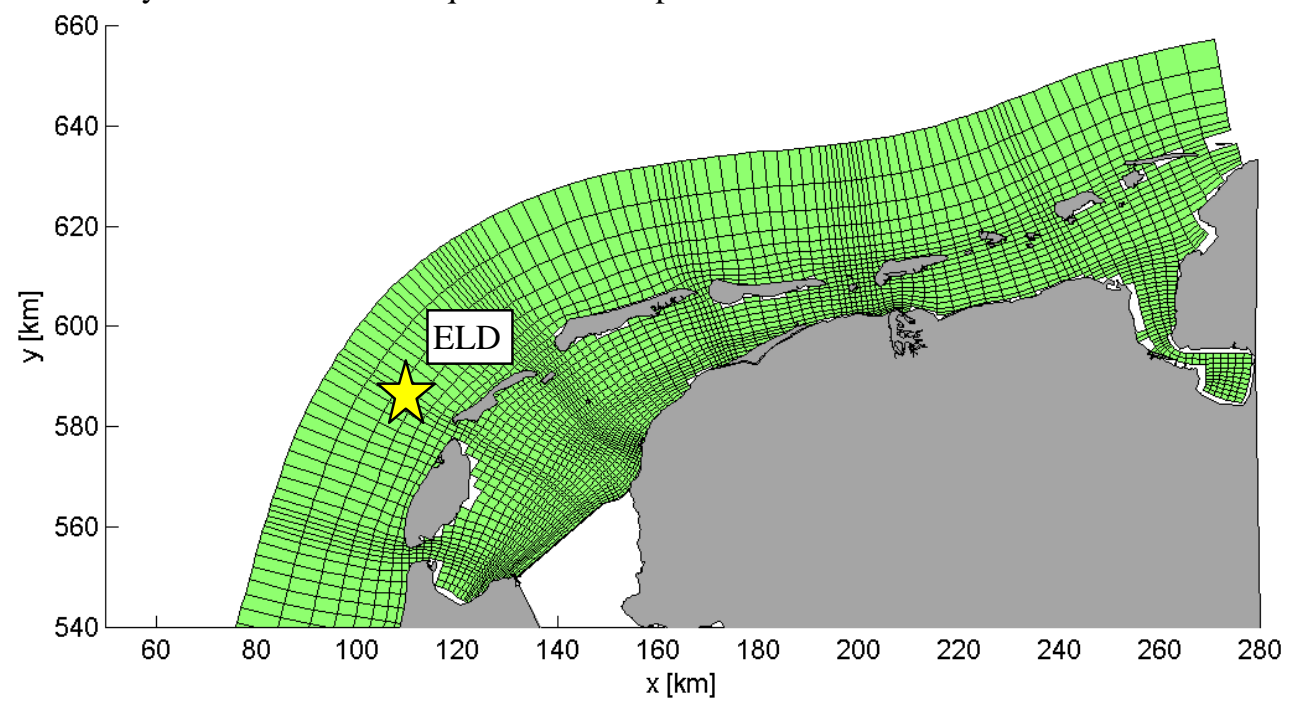

Figure 7. Kuststrook-Fijn grid (every $5^{\text {th }}$ grid line is shown). The grid extends further south along the coastline, but this is of less interest to the present study. ELD is a wave buoy location. 


\section{SWAN computations for method 1 and 2}

The SWAN computations have been carried out in stationary mode with SWAN version 40.72AB. Apart from the formulations suggested by Van der Westhuysen et al. (2007) for wind generation and whitecapping and the bi-phase model for depth-induced breaking, developed by Van der Westhuysen $(2009,2010)$, the default settings are applied.

The offshore boundary conditions are imposed as parameterized spectra. These spectra are assumed to have a Jonswap shape and are defined in terms of significant wave height and peak period. The values for these wave conditions are based on extreme value analyses for offshore buoy locations along the Dutch coast, assuming full correlation between wind and waves. The statistics of the wave parameters at wave buoy ELD (indicated in Fig. 7) are used. The resulting Jonswap spectra are applied along the entire offshore boundary. The wave direction is set equal to the wind direction. The directional spreading is set to 25 degrees. The eastern grid boundary in Germany and the southern boundary have open boundary conditions.

For method 1 combinations of 12 wind directions, 5 wind speeds and 7 water levels lead to 420 SWAN computations. For method 2, 5 time instants are considered in 40 storms, characterized by 5 basic wind speeds and 8 basic wind directions. Together with the 3 offshore surge levels and 3 phase differences between tide and maximum wind speed 1800 SWAN computations are performed for method 2. In each of the 1800 SWAN computations a uniform wind field, corresponding to the wind at the time instant during the WAQUA simulations is imposed. The spatially non-uniform water level and current fields from WAQUA are also used as input for the SWAN calculation. The offshore boundary conditions are based on a Jonswap spectrum, similar to method 1 . The results of the SWAN computations are interpolated to the regular matrix that is formed by the values of the variables of method 1 .

Results from both methods have been obtained at many locations along the coast of the Wadden Sea. For two locations, 371 in the Western Wadden Sea and 1153 in the eastern Wadden Sea (see Fig. 8), results for basic wind direction $300^{\circ} \mathrm{N}$ and basic wind speed $40 \mathrm{~m} / \mathrm{s}$ are investigated in more detail. In Fig. 9 and 10 the significant wave height and mean wave period are plotted against water level for both locations 1153 and 371 respectively. For method 1 this results in 7 values, corresponding to the number of water levels considered. For method $25 * 3 * 3$ values are available for this combination of wind speed and direction. These are indicated by red circles, to distinguish from results obtained for other wind speeds and directions.

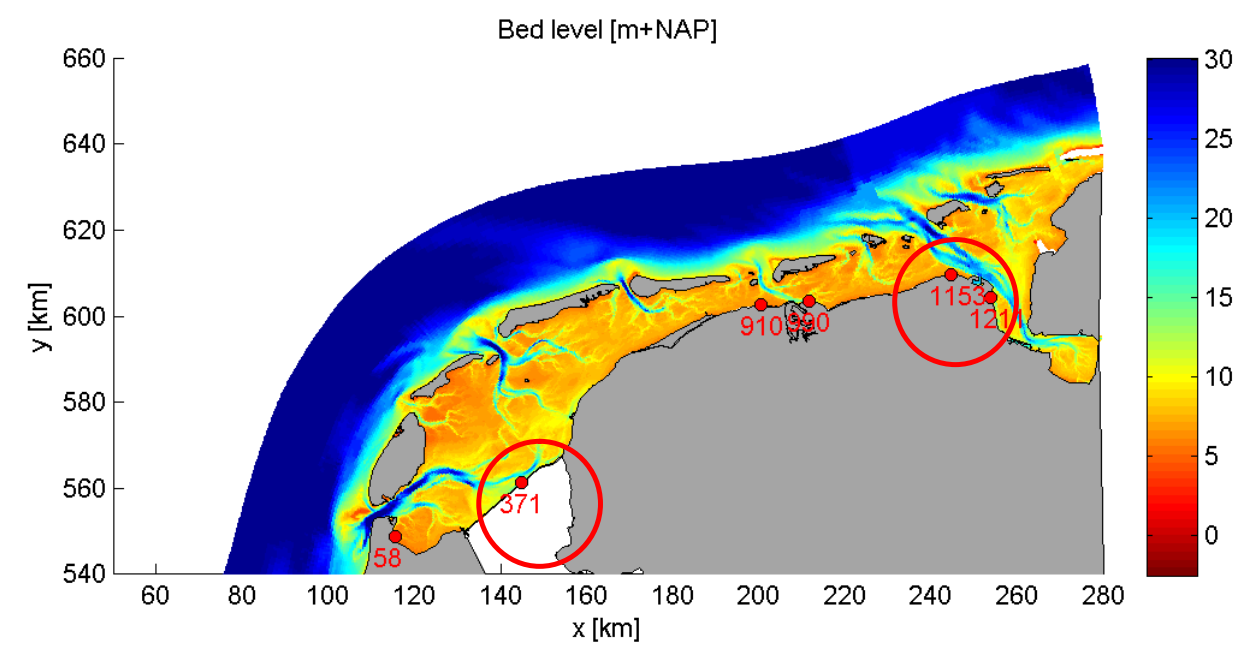

Figure 8. Bathymetry of Wadden Sea indicating the two locations of interest (371 and 1153).

The location 1153 is on the shallow flats of the Uithuizerwad. The small amount of scatter in $\mathrm{H}_{\mathrm{m} 0}$ and $\mathrm{T}_{\mathrm{m}-1,0}$ (see Fig. 9) for the west to north wind sector indicates a strong depth limitation of the wave conditions. The waves are at maximum height for this depth and the effect of turning winds and currents on the significant wave height is negligible. In contrast, the current does affect the wave period. Since the currents are mainly following the waves, the relative forcing decreases, or wave age increases, and the wave periods decrease, when the currents are included in method 2 . The decrease is $10-20 \%$ at location 1153 . The interpolated surface projections are good fits to the results. 

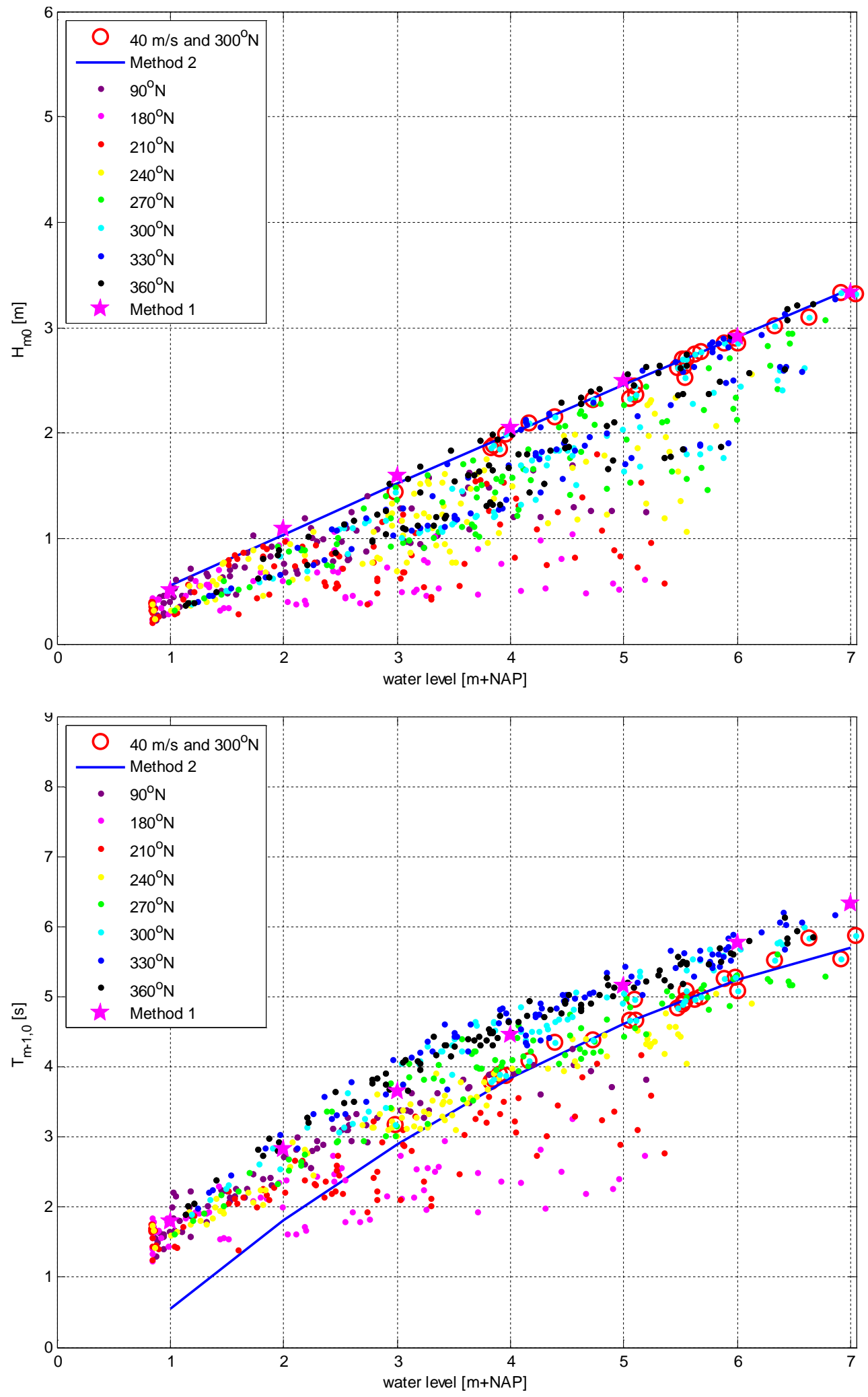

Figure 9. For location 1153 the significant wave height (upper panel) and mean wave period (lower panel) as function of water level obtained with method 1 for wind speed of $40 \mathrm{~m} / \mathrm{s}$ and wind direction of $300{ }^{\circ} \mathrm{N}$ and for all wind speeds and directions for method 2 . The blue line indicates the interpolated result of method 2 focusing on wind speed of $40 \mathrm{~m} / \mathrm{s}$ and wind direction of $300^{\circ} \mathrm{N}$. 

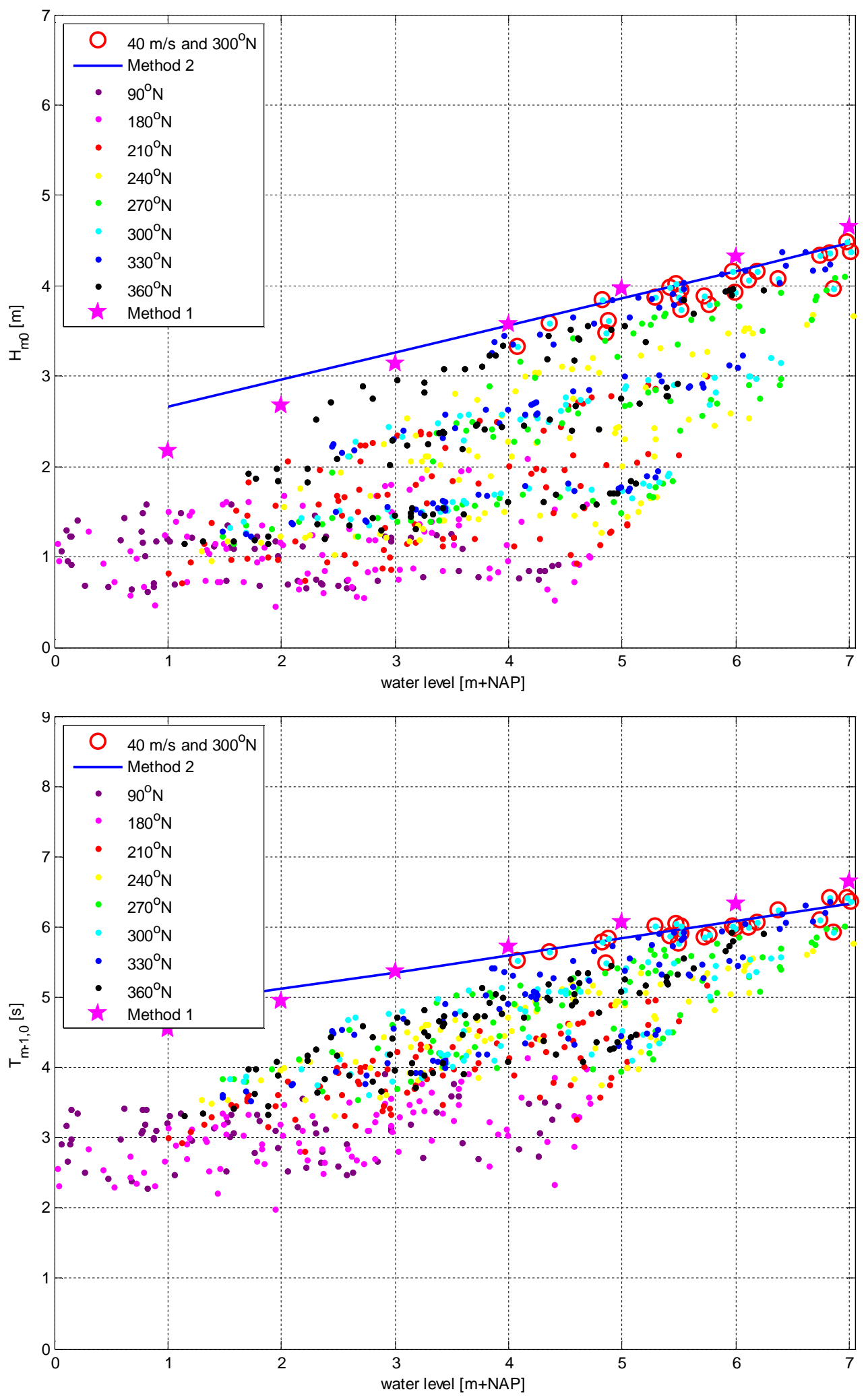

Figure 10. For location 371 the significant wave height (upper panel) and mean wave period (lower panel) as function of water level obtained with method 1 for wind speed of $40 \mathrm{~m} / \mathrm{s}$ and wind direction of $300{ }^{\circ} \mathrm{N}$ and for all wind speeds and directions for method 2 . The blue line indicates the interpolated result of method 2 focusing on wind speed of $40 \mathrm{~m} / \mathrm{s}$ and wind direction of $300{ }^{\circ} \mathrm{N}$. 
The total water depth at location 371 in front of the Afsluitdijk is larger than at the former location. Although there is still a clear depth-dependency on the significant wave height (see Fig. 10), the depth limitation is less than at the former location. The waves are not fully saturated and effects of currents on wave height and of water level gradient on both parameters are not negligible. This causes some scatter in the results. For the same water level at the location near the dike in method 1 and 2, the water level gradient in method 2 leads to water levels upwind that are smaller than the nearshore water level. Consequently, the significant wave height at upwind locations will be smaller, which affects the wave height at the dike location. The difference between wave heights from method 1 and method 2 varies between 0 and 10\%. The wave period obtained from method 2 is generally $10 \%$ smaller, due to a combination of the onshore water level tilt and a following current. The fits to the SWAN results are good.

\section{Hydra-K results}

The results of both methods were stored in two databases, which were used as input for Hydra-K to determine the normative wave conditions along the sea defenses in the Wadden Sea. For both methods, the normative significant wave height $\mathrm{H}_{\mathrm{m} 0}$ and mean wave period $\mathrm{T}_{\mathrm{m}-1,0}$ at the assessment water level are determined for all locations along the coast of the Wadden Sea. Fig. 11 focuses on the two regions around location 371 (Afsluitdijk) and 1153 (Groningen). For some locations, Hydra-K does not generate output, because these locations lie outside the coarse SWAN grid and there is no SWAN output. These locations form 'gaps' in the graphs of Fig. 11.
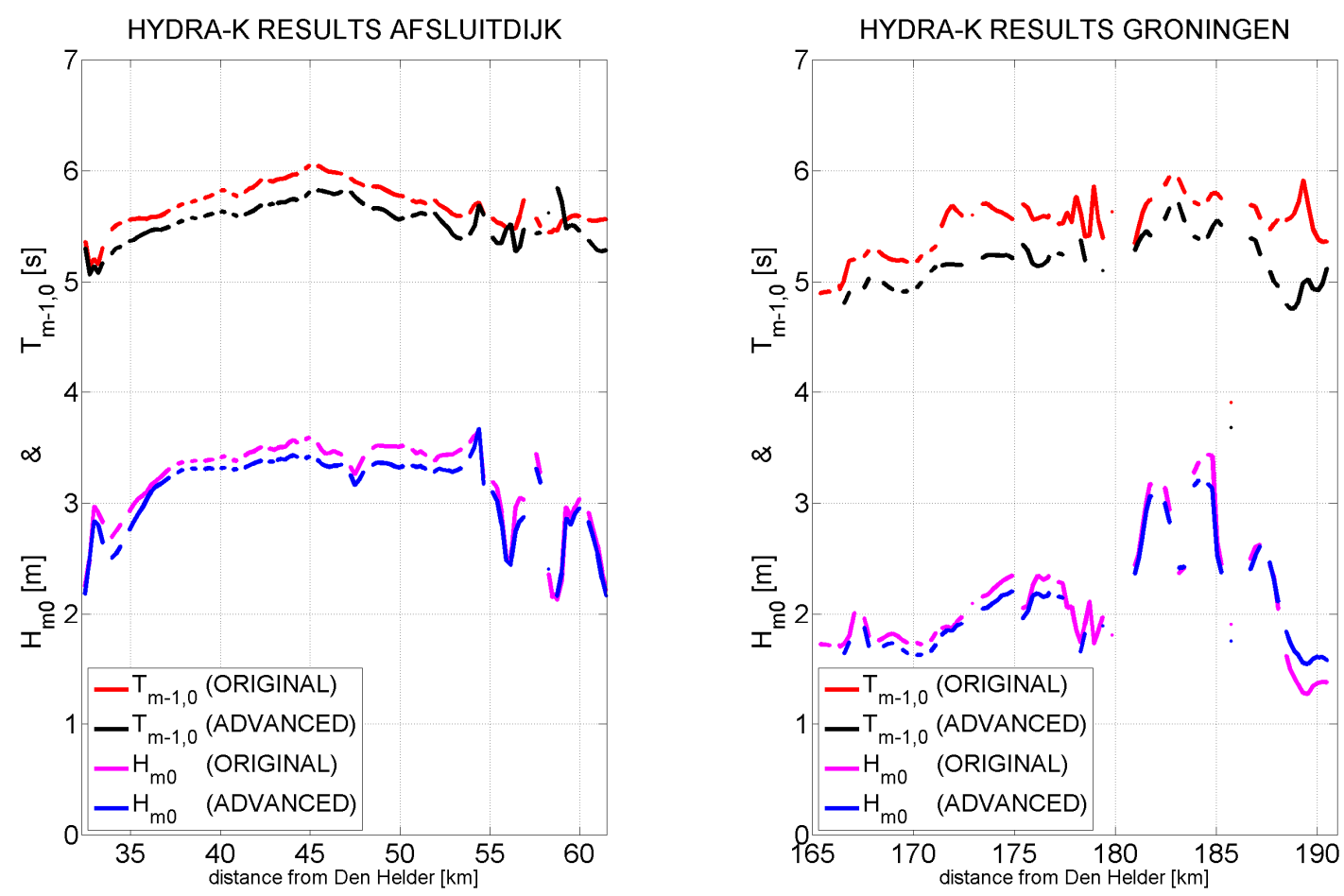

Figure 11. Hydra-K results for $H_{m 0}$ and $T_{m-1,0}$ for the original method (method 1) and the more advanced method (method 2) along the Afsluitdijk around location 371 (left plot) and the Groningen coast around location 1153 (right plot).

In general, the wave heights and wave periods obtained with method 1 are up to $10 \%$ larger than those obtained with the more advanced method 2, due to presence of water level gradients in method 2. The difference for the significant wave height is the same in the eastern part of the Wadden Sea. Differences up to $20 \%$ in mean wave period are obtained in this region. This may be attributed to the inclusion of currents in method 2 (see also Fig. 4). 


\section{CONCLUSIONS}

A probabilistic model has been developed to determine the HBC for the tidal inlet system of the Wadden Sea. Compared to the Holland coast and the Zeeland Delta the approach is more advanced now. Dynamic effects such as temporal changes in the wind, as well as currents, are shown to have a significant effect on the wave conditions in the Wadden Sea. Therefore these are included in the SWAN computations. The computational results are interpolated to a regular matrix, formed by wind speed, wind direction and water level, that is used as a look-up table in the probabilistic method Hydra-K to transform the offshore statistics to the load on the primary sea defenses.

In general the more advanced method leads to wave heights that are up to $10 \%$ lower and wave periods that are 10-20\% smaller than those obtained with the method that is presently applied for the Holland Coast and the Zeeland Delta. These differences can be ascribed to the inclusion of currents and water level gradients in the more advanced method. At depth-limited nearshore locations, the difference in significant wave heights from method 1 and 2 is negligible.

Although the results are obtained with computations on a relatively coarse grid a qualitative comparison can be made. The inclusion of relevant physics in the hydrodynamic computations produces more realistic and credible HBC. Therefore the more advanced method will be applied to determine the HBC for 2011.

\section{ACKNOWLEDGMENTS}

This study is part of the WTI (in Dutch: 'Wettelijk Toetsinstrumentarium') project commissioned by Rijkswaterstaat Centre for Water Management in the Netherlands.

\section{REFERENCES}

Alkyon (2008) Simulation studies for storm winds, flow fields and wave climate in the Wadden Sea. Alkyon report A2108, November 2008. Authors: G. Lipari and G.Ph. van Vledder.

De Haan, L. and S.I. Resnick (1977). Limit theory for multivariate sample extremes, Z.Warscheinlichkeittheorie verw. Gebiete 40, 317-337.

Deltares (2009). The evolution of storms on the Wadden Sea. Deltares report 1200264.004, November 2009. Authors: J. Lopez de la Cruz, A. Tijssen and J.V.L. Beckers.

Groeneweg, J., M. van Ledden and M. Zijlema (2006). Wave transformation in front of the Dutch coast. In Proc. of the Int. Conf. on Coastal Engng, San Diego, pp. 552-564.

Van der Westhuysen, A.J., M. Zijlema and J.A. Battjes (2007). Nonlinear saturation-based whitecapping in SWAN for deep and shallow water. Coastal Eng., Vol. 54, 151-170.

Van der Westhuysen, A.J. (2009). Modelling of depth-induced wave breaking over sloping and horizontal beds. Proc. 11th International Workshop on Wave Hindcasting and Forecasting.

Van der Westhuysen, A.J. (2010). Modelling of depth-induced wave breaking under finite-depth wave growth conditions. Journal of Geophysical Research, Vol. 115, C01008, doi:10.1029/2009JC005433.

Van Dongeren, A.R., A.J. van der Westhuysen, J. Groeneweg, G.Ph. van Vledder, J. Lansen, A. Smale, C. Gautier, H. Peters and I. Wenneker (2010). Spectral wave modelling in tidal inlet seas: Results from the SBW Wadden Sea project. To appear in Proc. Int. Conf. on Coastal Engng, Shanghai, China.

Wieringa, J.W. and P.J. Rijkoort (1983). Windklimaat van Nederland (In Dutch). Staatsdrukkerij, 's Gravenhage (NL). 